Original Article

\title{
Application of Lateral Wedge in Knee Osteoarthritis for Improving Pain and Quality of Life
}

\author{
Abdul Salam, Waqar Ahmad Awan, Tahir Mahmood, Muhammad Shah Rukh, Nimra Seffat
}

\begin{abstract}
OBJECTIVE: To determine the effectiveness of lateral wedge with and without conventional physiotherapy in relieving knee pain and quality of life in patients of knee Osteoarthritis.

METHODOLOGY: This Randomized controlled study was conducted in Madina Clinics, Faisalabad. By using simple random technique 40 patients in range 40-60 years of age with clinically and radiologically diagnosed cases of grade II and III were studied, from February to August 2016. Subjects were divided in two groups with 20 subjects in each group. KOOS knee survey was used for the assessment of Quality of life.

RESULTS: Mean total pain score on baseline of experimental group was $79.95 \pm 2.5$ while the score amongst the control group was 79.95 \pm 7.69 , after application of lateral wedges along with other treatments, score after $2^{\text {nd }}$ week was $84.65 \pm 2.94$ while in control group was $80.25 \pm 2.9 .97$. After $4^{\text {th }}$ week the symptoms score in experimental group was $83.00 \pm 0.00$ while control group was $88.95 \pm 2.96$. After the $6^{\text {th }}$ week score was $91.5 \pm 14.5$ of experimental and $81.8 \pm 9.5$ of control group.These results of insole Wedges is also correlated with a lateral shift in the location of the COP in stance phase. Increase in the knee joint varus moment with insole Wedges suggests that the indication and limitations of laterally wedged insoles in general should be analysed in detail.
\end{abstract}

CONCLUSION: This study concluded that the lateral wedges were significant in reduction of pain and symptoms as well as improve the quality of life

KEYWORDS: Knee Osteoarthritis, Quality of Life, Lateral Wedge

This article may be cited as: Salam A, Awan WA, Mahmood T, Rukh MS, Seffat N. Application of Lateral Wedge in Knee Osteoarthritis for Improving Pain and Quality of Life. J Liaquat Uni Med Health Sci. 2019;18(02):146-51. doi: 10.22442/jlumhs.191820618

\section{INTRODUCTION}

Osteoarthritis is also known as degenerative joint disease and progressive disorder of the joint that is due gradual loss of cartilage and resulting in development of bony spur and cysts in the margin of joints ${ }^{1 .}$ The non-surgical treatment that will reduce medial load on the knee joint is lateral wedge an inexpensive readily available treatment- that will show to reduce medial knee load. OA has prevalence that is age dependent, it's higher in age of 50 years male as compared to females. Women after 50 years are more affected $^{2}$. There was more incidences seen in female $(34 \%)$ and male $(31 \%)$ and symptomatic proportion was found $11 \%$ in female and $7 \%$ in $\operatorname{man}^{3}$.

Overall prevalence of self-reported $\mathrm{OA}$ in the total sample was $14.8 \%$, where $10.5 \%$ of individuals reported having knee $\mathrm{OA}$ and $8.5 \%$ reported having hip OA. Differences in prevalence were found for males and females across age categories for both knee and hip $\mathrm{OA}^{4}$. Lateral wedged insoles have been shown to help clinically alleviate pain associated with medial compartment osteoarthritis ${ }^{5}$. It is not known whether incorporating a lateral wedge into a custom-molded foot orthotics will achieve similar results $^{6}$. Clinical management is hampered by lack of knowledge about their mechanism of effect ${ }^{7}$. Some people report increased pain associated with cold temperature, high humidity, and/or a drop in barometric pressure, but studies have had mixed results $^{8}$. As OA progresses, the affected joints appear larger, are stiff and painful, and usually feel better with gentle use but worse with excessive or prolonged use, thus distinguishing it from rheumatoid arthritis. Bone spurs develop in osteoarthritis 9 . Prevalence was higher in older individuals and women. African Americans had higher prevalence of knee symptoms, radiographic knee $\mathrm{OA}$, and symptomatic knee OA, but significantly higher prevalence of severe radiographic knee OA compared to Caucasians ${ }^{10}$. Radiographic changes of osteoarthritis of the knee (definite narrowing with or without arthritic features) were bilateral in $85 \%$ of patients ${ }^{11,12}$. Quality of life (QOL) is the basic well-being of individuals and societies, outlining negative and positive highlights of life. This observes life satisfaction, including everything from physical health, family, education, employment, riches, religious beliefs, finance and the environment ${ }^{13}$. There is evidence to indicate that physiotherapy interventions can reduce knee pain and 
improve function in those with knee $\mathrm{OA}^{14}$.

There is some confirmation that physiotherapy in blend with other administration systems, for example, weight reduction and regard for mental components may give more huge results than any of these in isolation $^{15}$.

However, limited research data is available in Pakistan to show any significant impact of lateral wedge on the symptoms and improving quality of life of patients of knee osteoarthritis. The study will be beneficial in improvement in quality of life and decrease symptoms of OA.

\section{METHODOLOGY}

This was a randomized controlled trail study. The duration of study was 6 months from February to August 2016. Data was collected from the patient coming in Madina clinic of physiotherapy, University of Faisalabad. The study included subjects with 40-60 years of age at Madina clinics were studied. Clinically and radio-logically diagnosed cases of medial compartment knee OA grade II and III were included. The sample was calculated on supposed population 1000 and Confidence interval 95\% and response distribution was $90 \%$. The sample size was 41 (www.raosoft.com/samplesize).We arranged two groups with the groups of 20 each by odd even numbers. Every first patient in criteria was in control and next was included in experimental group. This reduced chances of biased selection. Total 40 subjects with knee osteoarthritis fulfilling the inclusion criteria were studied. Subjects with Rheumatoid arthritis, fracture, tumor, or trauma or with any other systemic co-morbidity having age less than 40 and more than 60 were excluded.

In control group conventional physical therapy Ultrasound, SWD and Quadriceps isomeric exercises 5 times in a week up to 6 weeks. The aim was provision of lateral wedge along with conventional physical therapy to relieve pain and improve quality of life. Ultrasound, SWD and isometric exercises of quadriceps in both groups were applied 5 times in a week up to 6 weeks. Experimental group throughout week in day time Lateral wedge (thickness $7 \mathrm{~mm}$ ) was applied in them. Duration of each session was 35 minutes. Ultrasound therapy as per the patient's requirement with an intensity of 1.5 watts $/ \mathrm{cm} 2$ for 5 minutes in continuous mode at the tender point around the knee joint. SWD was used for 15 minutes to help to relieve pain and swelling. Isometric exercise the most appropriate and easy to perform by the patients and can be easily and safely performed for a period of 15 minutes.

Outcome measurement tool used was KOOS knee survey. Data was taken at baseline and after every 2 weeks i.e at the end of $2^{\text {nd }}, 4^{\text {th }}$ and $6^{\text {th }}$ week. The results of study were presented as frequency, percentages, mean $\pm S D$ and $p$-value. For between groups, cross-sectional comparison, Independent sample t-test was used and for within the groups repeated measures ANOVA was used.

\section{RESULTS}

Study was conducted to find out that how much lateral wedges are effective in knee joint Osteoarthritis. According to the data analysis there were $n=40$ participants satisfying inclusion and exclusion criteria. There were 2 groups, $n=20$ subjects of knee osteoarthritis with medial joint space reduction in each group assigned randomly. Data analysis shows that the mean age of all the patients was $4.18 \pm 5.90$. There was $n=33$ Male and $n=7$ females, amongst these patients $n=5$ were with normal BMI while $n=35$ were overweight. Mostly were in normal BMI Range (18.524.5), so their risk of obesity to effect the result was decreased. Statistical analysis shows that between the two group experimental group shows more improvement than the control one as the $p$ value $=$ $<0.05$, which was further justified by the mean score of the question being asked from all patients about their Symptoms. Bending knee Mean score of symptom bending zero week of experimental group was $3.65 \pm .489$ while the score amongst the control group was $4.00 \pm 0.00$. (Table I) (Mean score of knee stiffness during zero week of experimental group was $3.50 \pm .607$ while the score amongst the control group was $4.00 \pm 0.00$. Similarly Pain was assessed and found that according to KOOS scoring 100 points indicate perfect condition while worst condition indicated by 0 Which clearly elaborates that lateral wedges reduces the pain more significantly then the normal physical therapy intervention (Table II). Mean score of quality of life total score during zero week of experimental group was $10.95 \pm 12.5$ while the score amongst the control group was 2.5 \pm 7.69 . (Table III). After application of lateral wedges along with other rehabilitation protocols mean score after $2^{\text {nd }}$ week was $36.0 \pm 11.92$ while the mean score of control group was $10.65 \pm 10.97$. After $4^{\text {th }}$ week the symptom score was recorded in experimental group was $52.25 \pm 12.46$ while control group score was $23.5 \pm 2.66$. After the 6 th week or last week the mean score was $70.70 \pm 14.5$ of experimental and $28.8 \pm 9.5$ of control group. According to KOOS scoring 100 points indicate perfect condition while worst condition indicated by 0 Which clearly elaborates that lateral wedges enhances the QOL more significantly then the normal physical therapy interventions (Table IV). 
Abdul Salam, Waqar Ahmad Awan, Tahir Mahmood, Muhammad Shah Rukh, Nimra Seffat

TABLE I: DESCRIPTIVE STATISTICS BETWEEN THE GROUP ABOUT MORNING STIFFNESS

\begin{tabular}{|l|l|l|r|c|}
\hline & Groups & Mean & $\begin{array}{c}\text { Std. } \\
\text { Deviation }\end{array}$ & P-value \\
\hline \multirow{2}{*}{$\begin{array}{l}\text { Stiffness } \\
\text { morning (0 week) }\end{array}$} & Group A & 3.50 & .607 & \multirow{2}{*}{0.00} \\
\cline { 2 - 4 } & Group B & 4.00 & .000 & \\
\hline $\begin{array}{l}\text { Stiffness morning } \\
\text { (After 2nd week) }\end{array}$ & Group A & 2.75 & .716 & \multirow{2}{*}{0.00} \\
\cline { 2 - 4 } & Group B & 3.75 & .444 & \\
\hline $\begin{array}{l}\text { Stiffness } \\
\text { morning (After 4th } \\
\text { week) }\end{array}$ & Group A & 2.10 & .641 & \multirow{2}{*}{0.00} \\
\cline { 2 - 4 } $\begin{array}{l}\text { Stiffness } \\
\text { morning (After 6th } \\
\text { week) }\end{array}$ & Group B & 3.00 & .000 & \\
\cline { 2 - 4 } & Group A & 1.60 & .883 & \multirow{2}{*}{0.00} \\
\hline
\end{tabular}

TABLE II: DESCRIPTIVE STATISTICS BETWEEN THE GROUP MEAN PAIN ASSESSMENT

\begin{tabular}{|l|l|l|r|c|}
\hline & Groups & Mean & $\begin{array}{c}\text { Std. } \\
\text { Deviation }\end{array}$ & P-value \\
\hline $\begin{array}{l}\text { Pain total zero } \\
\text { week }\end{array}$ & Group A & 79.9500 & 2.62528 & \multirow{2}{*}{0.00} \\
\cline { 2 - 4 } & Group B & 79.2500 & 2.22131 & \\
\hline \multirow{2}{*}{$\begin{array}{l}\text { Pain total } 2^{\text {nd }} \\
\text { week }\end{array}$} & Group A & 84.6500 & 2.94288 & \multirow{2}{*}{0.00} \\
\cline { 2 - 4 } & Group B & 80.2500 & 2.22131 & \\
\hline \multirow{2}{*}{$\begin{array}{l}\text { Pain total } 4^{\text {th }} \\
\text { week }\end{array}$} & Group A & 88.9500 & 2.98196 & \multirow{2}{*}{0.00} \\
\cline { 2 - 4 } & Group B & 83.0000 & .00000 & \\
\hline \multirow{2}{*}{$\begin{array}{l}\text { Pain total score } \\
6^{\text {th }} \text { week }\end{array}$} & Group A & 91.4500 & 4.21120 & \multirow{2}{*}{0.00} \\
\cline { 2 - 4 } & Group B & 81.7500 & 2.22131 & \\
\hline
\end{tabular}

TABLE III: DESCRIPTIVE STATISTICS REPEATED MEASURE ANOVA OF QUESTION PAIN TOTAL

\begin{tabular}{|c|c|c|c|c|c|c|c|}
\hline \multirow{2}{*}{\multicolumn{2}{|c|}{ Repeated Measure Anova }} & \multicolumn{3}{|c|}{ Experimental group $(n=20)$} & \multicolumn{3}{|c|}{ Control group $(n=20)$} \\
\hline & & Mean & SD & p-value & Mean & SD & p-value \\
\hline \multirow{8}{*}{$\begin{array}{c}\text { PAIN } \\
\text { TOTAL }\end{array}$} & At zero week & 79.9 & 2.62 & \multirow{2}{*}{0.00} & 79.2 & 2.22 & \multirow{2}{*}{0.00} \\
\hline & After 2 weeks & 84.6 & 2.94 & & 80.2 & 2.22 & \\
\hline & After 2 weeks & 84.6 & 2.94 & \multirow{2}{*}{0.00} & 80.2 & 2.22 & \multirow{2}{*}{0.00} \\
\hline & After 4 weeks & 88.9 & 2.98 & & 83 & .00 & \\
\hline & At zero week & 79.9 & 2.62 & \multirow{2}{*}{0.00} & 79.2 & 2.22 & \multirow{2}{*}{0.00} \\
\hline & After $4^{\mathrm{TH}}$ weeks & 88.9 & 2.98 & & 83 & .00 & \\
\hline & At zero week & 79.9 & 2.62 & \multirow{2}{*}{0.00} & 79.2 & 2.22 & \multirow{2}{*}{0.00} \\
\hline & At $6^{\text {TH }}$ week & 91.4 & 4.21 & & 81.7 & 2.22 & \\
\hline
\end{tabular}

According to the table above experimental group shows significant improvement then control group suggested by mean score improvement and $P$ value $<0.05$

TABLE IV: DESCRIPTIVE STATISTICS BETWEEN THE GROUP QOL ASSESSMENT

\begin{tabular}{|l|l|r|r|c|}
\hline & Groups & Mean & $\begin{array}{c}\text { Std. } \\
\text { Deviation }\end{array}$ & P-value \\
\hline \multirow{2}{*}{$\begin{array}{l}\text { QOL total zero } \\
\text { week }\end{array}$} & Group A & 10.950 & 12.56761 & \multirow{2}{*}{0.00} \\
\cline { 2 - 4 } & Group B & 2.5000 & 7.69484 & \\
\hline \multirow{2}{*}{$\begin{array}{l}\text { QOL total } \\
\text { week }\end{array}$} & Group A & 36.000 & 11.90312 & \multirow{2}{*}{0.00} \\
\cline { 2 - 4 } & Group B & 10.650 & 10.97497 & \\
\hline \multirow{2}{*}{$\begin{array}{l}\text { QOL total } 4^{\text {th }} \\
\text { week }\end{array}$} & Group A & 52.250 & 12.46416 & \multirow{2}{*}{0.00} \\
\cline { 2 - 4 } & Group B & 23.500 & 2.66557 & \\
\hline \multirow{2}{*}{$\begin{array}{l}\text { QOL total 6 } \\
\text { week }\end{array}$} & Group A & 70.700 & 14.58225 & \multirow{2}{*}{0.00} \\
\cline { 2 - 4 } & Group B & 28.850 & 9.59317 & \\
\hline
\end{tabular}

\section{DISCUSSION}

Statistical analysis shows that the lateral wedges are significant in reduction of pain and symptoms associated with osteoarthritis and improve the quality of life and enhances the sports and functional ability of the patient by reducing the biomechanical load on the knee joint.

The goal of the wedged orthotic is to indirectly realign the knee by altering foot alignment. Moment reductions have been reported in healthy subjects fitted with a 5 to 10 degree lateral wedge ${ }^{10,16}$. The lack of difference in peak knee adduction is similar to reports by previous authors who found no effect of the wedged orthosis on frontal plane knee motion of healthy individuals ${ }^{17}$.

Another study reported that patients with knee osteoarthritis have greater knee laxity than healthy controls ${ }^{18}$. Therefore, they may be more amenable to realignment than a healthy population. Although no significant difference was observed between conditions for peak knee adduction, most subjects demonstrated a decrease for this variable in the wedged condition. A subgroup responded in the opposite direction, actually increasing peak knee adduction (1.4-2.8 degrees) in the wedged condition ${ }^{19}$. The laterally wedged orthotic device was expected to 
increase rear foot eversion and therefore reduce knee adduction. On average, peak eversion increased by 1.7 degrees in the wedged condition. However, in the subgroup, peak eversion only increased 0.3 degrees. Our finding suggests that the subgroup may have compensated at the rear foot for the orthotic differently than the majority of the subjects. These subjects may have accounted for the lack of significance found in peak knee adduction.

Knee adduction excursion was significantly reduced even though the mean reduction was 0.7 degrees. However, 12 of 20 subjects exhibited at least a $10 \%$ reduction. However, if the reduction leads to a lateral shift in the contact forces in the knee, this may slow down the progression of the disease. As well, a reduction in adduction excursion could prevent the medial shift of the contact force and reduce the frontal plane moment at the knee. The laterally wedged device significantly reduced the first peak knee adduction moment. The amount of wedging needed for maximal pain relief increased as the subjects' K-L grade worsened, suggesting that greater wedging was needed for more advanced knee $\mathrm{OA}^{20}$. On average, each K-L group exhibited approximately a $10 \%$ reduction in the first peak knee adduction movement, which is similar to previous research. Previous research on unloading braces observed a similar $11 \%$ reduction in the frontal plane moment with the brace ${ }^{21}$. Although $10 \%$ may be considered small, it may be clinically significant when repeated over thousands of foot strikes per day. There have been few reports on the effects of wearing a laterally wedged insole on the angle and moment at the subtalar joint. In another $r$ study found that, in a static standing position, the laterally wedged insole increased the valgus angle of the subtalar joint, and therefore reduced the load in the medial compartment of the knee joint ${ }^{2}$. Page CJ $2011^{15}$ suggested that during walking an increased valgus angle of the subtalar joint obtained by a laterally wedged insole might be effective for the reduction of knee pain in OA patients. In our study, the subtalar joint valgus angle did not increase significantly with the laterally wedged insole. It was assumed that the effect of wearing the laterally wedged insole on the subtalar joint angle during gait was not systematic among the subjects, in particular among OA patients ${ }^{22}$. In contrast, our previous study 11 and this one indicate that wearing a laterally wedged insole had the same effect on the increased subtalar joint valgus moment during gait in people with and without knee OA. We found that wearing a laterally wedged insole significantly increased the valgus moment arm of the subtalar joint, creating a lateral shift in COP location. Although the beneficial effect of reducing knee joint Varus moment with a laterally wedged insole were evident in both the healthy elders and the patients with $O A$, the patients with $\mathrm{OA}$ wearing such an insole had significantly greater knee joint Varus moments during gait compared with healthy elders ${ }^{23}$, this finding could be interpreted as follows: the $6^{\circ}$ lateral wedge seems to have a range of effectiveness where it successfully reduces the varus moments in OA patients. Although wearing $A 6^{\circ}$ lateral wedge reduced the varus moment significantly, it was unable to reduce it to normative levels. Kerrigan et $\mathrm{al}^{9}$ showed that wearing a $10^{\circ}$ lateral wedge further reduced the knee joint varus moment; however, it was associated with varying degrees of discomfort. Furthermore, it was assumed that the presence of knee OA was sufficient to generate differences in knee joint biomechanics during gait from age matched, healthy elders ${ }^{24,25}$. The dissimilarities in the tibio-femoral angle between the healthy elders and the OA patients were accompanied by differences in the knee varus angle and moment during stance phase. Non-surgical treatment was good but compared to TKR which is surgical procedure along with Insoles, exercise were more beneficial. Non-surgical alone was not as much effective as surgical ${ }^{26}$.

\section{CONCLUSION}

The results of study were significant in reduction of pain and symptoms associated with osteoarthritis and improve the quality of life. There was also enhancement in the sports activities and functional ability of the patient as there was reduction in the biomechanical load on the knee joint. Wedges soles use suggests that these are indicated but there are also limitations of laterally wedged insoles.

\section{LIMITATIONS}

In general it should be analysed in more detail with possibly more sample size leading to new guidelines for the use of such wedged insoles.

Ethical Permission: ERC reference No. 1402-PDPT008 dated: 23-02-2016.

Conflict of interest: None declared

Funding: None declared.

\section{REFERENCES}

1. Ng NT, Heesch KC, Brown WJ. Strategies for managing osteoarthritis. Int J Behav M. 2012; 19 (3): 298-307. doi: 10.1007/s12529-011-9168-3.

2. Knapik JJ, Pope R, Orr R, Schram B. Osteoarthritis: Pathophysiology, Prevalence, Risk Factors, and Exercise for Reducing Pain and Disability. J 
Spec Oper Med. 2018; 18(3): 94-102.

3. Han A, Gellhorn AC. Trajectories of quality of life and associated risk factors in patients with knee osteoarthritis: findings from the Osteoarthritis Initiative. Am J Phys Med Rehabil. 2018; 97(9): 620-7. doi: 10.1097/PHM.0000000000000926.

4. Shameen T, Thangamani S, Naseeb F. A Prospective Study on Prevalence and Risk Factors among Knee Osteoarthritis Patients in a Tertiary Care Hospital. Int J Novel Trends Pharm Sci. 2018; 8(3): 72-75.

5. Crenshaw SJ, Pollo FE, Calton EF. Effects of lateral-wedged insoles on kinetics at the knee. Clin Orthop Relat Res. 2000; 375:185-92.

6. Rubin R, Menz HB. Use of laterally wedged custom foot orthoses to reduce pain associated with medial knee osteoarthritis: a preliminary investigation. J Am Podiatr Med Assoc. 2005; 95 (4): 347-52.

7. Rafiaee M, Karimi MT. The effects of various kinds of lateral wedge insoles on performance of individuals with knee joint osteoarthritis. Int J Prev Med. 2012; 3(10): 693-98.

8. Muraki S, Oka H, Akune T, Mabuchi A, En-Yo Y, Yoshida $\mathrm{M}$, et al. Prevalence of radiographic knee osteoarthritis and its association with knee pain in the elderly of Japanese population-based cohorts: the ROAD study. Osteoarthritis Cartilage. 2009; 17(9): 1137-43. doi: 10.1016/j.joca.2009.04.005.

9. Andrianakos AA, Kontelis LK, Karamitsos DG, Aslanidis SI, Georgountzos Al, Kaziolas GO, et al. Prevalence of Symptomatic Knee, Hand, and Hip Osteoarthritis in Greece. The ESORDIG study. J Rheumatol. 2006; 33(12): 2507-13.

10. Jordan JM, Helmick CG, Renner JB, Luta G, Dragomir AD, Woodard $J$, et al. Prevalence of knee symptoms and radiographic and symptomatic knee osteoarthritis in African Americans and Caucasians: the Johnston County Osteoarthritis Project. J Rheumatol. 2007; 34(1): 172-80.

11. Ledingham J, Regan $M$, Jones A, Doherty $M$. Radiographic patterns and associations of osteoarthritis of the knee in patients referred to hospital. Ann Rheum Dis. 1993; 52(7):520-6. doi: 10.1136/ard.52.7.520

12. Blendea D. Experience Of Targeted Radiofrequency Therapy Applied In Medical Recovery. Journal: Conference proceedings of eLearning and Software for Education (eLSE); 2016; 3: 322-25.

13. Vincent KR, Conrad BP, Fregly BJ, Vincent HK. The pathophysiology of osteoarthritis: a mechanical perspective on the knee joint. PM R. 2012; 4(5 Suppl): S3-S9. doi:10.1016/j.pm rj.2012.01.020.

14. Stark J, Lund R, Nelson C and Rogers B. (2001). Method of optimizing isometric exercise. US 6,296, 595 B1 (Patent).

15. Page CJ, Hinman RS, Bennell KL. Physiotherapy management of knee osteoarthritis. Int $\mathrm{J}$ Rheum Dis. 2011; 14(2): 145-51. doi: 10.1111/j.1756185X.2011.01612.x.

16. Figueiredo EC, Figueiredo GC, Dantas RT. Influence of meteorological elements on osteoarthritis pain: A Review of the literature. Rev Bras reumatol. 2011; 51(6): 622-8. doi: 10.1590/ S0482-50042011000600008

17. Bijlsma JW, Berenbaum F, Lafeber FP. Osteoarthritis: an update with relevance for clinical practice. Lancet. 2011; 377(9783): 211526. doi: 10.1016/S0140-6736(11)60243-2.

18. Fernandes JC, Martel-Pelletier J, Pelletier JP. The role of cytokines in osteoarthritis pathophysiology. Biorheology. 2002; 39(1-2): 237-46.

19. Hatfield GL, Cochrane CK, Takacs J, Krowchuk NM, Chang R, Hinman RS, et al. Knee and ankle biomechanics with lateral wedges with and without a custom arch support in those with medial knee osteoarthritis and flat feet. J Orthop Res. 2016; 34(9): 1597-605. doi: 10.1002/jor.23174.

20. Edwards $M H$, Parsons $C$, Bruyère $O$, Petit Dop $F$, Chapurlat R, Roemer FW, et al. High Kellgren-Lawrence grade and bone marrow lesions predict worsening rates of radiographic joint space narrowing; The SEKOIA study. J Rheumatol. 2016; 43(3): 657-65. doi: 10.3899/ jrheum.150053.

21. Srikanth VK, Fryer JL, Zhai G, Winzenberg TM, Hosmer D, Jones G. A meta-analysis of sex differences prevalence, incidence and severity of osteoarthritis. Osteoarthritis Cartilage. 2005; 13 (9): 769-81.

22. Chapman GJ, Parkes MJ, Forsythe L, Felson DT, Jones RK. Ankle motion influences the external knee adduction moment and may predict who will respond to lateral wedge insoles?: an ancillary analysis from the SILK trial. Osteoarthritis and cartilage. 2015; 23(8): 1316-22. doi: 10.1016/j. joca.2015.02.164.

23. Schween R, Gehring D, Gollhofer A. Immediate effects of an elastic knee sleeve on frontal plane gait biomechanics in knee osteoarthritis. PLoS One. 2015; 10(1): e0115782. doi: 10.13 71/ journal.pone.0115782

24. Dumond H, Presle N, Terlain B, Mainard D, 
Loeuille D, Netter P, et al. Evidence for a key role of leptin in osteoarthritis. Arthritis Rheumatol. 2003; 48(11): 3118-29.

25. Teeple E, Jay GD, Elsaid KA, Fleming BC. Animal models of osteoarthritis: challenges of model selection and analysis. AAPS J. 2013; 15(2): 43846. doi: 10.1208/s12248-013-9454-X.
26. Skou ST, Roos EM, Laursen MB, Rathleff MS, Arendt-Nielsen L, Rasmussen S, et al. Total knee replacement and non-surgical treatment of knee osteoarthritis: 2-year outcome from two parallel randomized controlled trials. Osteoarthritis Cartilage. 2018; 26(9): 1170-80. doi: 10.1016/j. joca.2018.04.014

\begin{tabular}{|l|} 
AUTHOR AFFILIATION: \\
Abdul Salam (Corresponding Author) \\
Assistant Professor, Department of Physical Therapy \\
Sialkot Medical College, Sialkot, Punjab-Pakistan. \\
Email: abdulsalamrana@yahoo.com \\
Dr. Waqar Ahmad Awan \\
Associate Professor \\
Faculty of Rehabilitation \& Allied Sciences (FRAHS) \\
Riphah International University, Islamabad-Pakistan. \\
Tahir Mahmood \\
Lecturer/ Physiotherapist \\
Bahawalpur Medical and Dental College \\
Bahawalpur, Punjab-Pakistan. \\
Muhammad Shah Rukh \\
Head of Physiotherapy Department \\
Islamabad Medical and Dental College \\
Islamabad-Pakistan. \\
Nimra Seffat \\
Internee Physiotherapist \\
Children Hospital Lahore, Punjab-Pakistan.
\end{tabular}

